How Well Can the Theory of Planned Behavior Account for Occupational Intentions?

\author{
John Arnold, John Loan-Clarke, Crispin Coombs and Adrian Wilkinson \\ The Business School \\ Loughborough University \\ UK \\ Jenny Park \\ School of Nursing \\ Nottingham University, UK
}

\author{
Diane Preston \\ Open University \\ UK
}

November 2005

Correspondence to: Professor John Arnold, The Business School, Loughborough University, Ashby Road, Loughborough, LE11 3TU, UK j.m.arnold@lboro.ac.uk, +44 (0)1509 223121 


\title{
How Well Can the Theory of Planned Behavior Account for Occupational Intentions?
}

\author{
Abstract \\ The theory of planned behavior (TPB) has been used extensively to predict a wide range of \\ behavior and behavioral intention, but little of this research has been in the vocational realm. \\ We advance on existing knowledge by testing the capacity an extended version of TPB to \\ explain intentions to work for the UK’s National Health Service as a nurse, physiotherapist or \\ radiographer amongst three groups in contrasting situations: professionally unqualified $(\mathrm{N}=$ \\ 507), in professional training $(\mathrm{N}=244)$, and professionally qualified $(\mathrm{N}=227)$. We also \\ examine the role of alternative career intentions. Our results provide strong confirmation for \\ attitude and subjective norm as predictors of behavioral intention, with or without controlling \\ for alternative career intentions. There is some support for perceived behavioral control as a \\ predictor of intention, but less for moral obligation and identity. As hypothesised, attitude is a \\ stronger predictor of intention amongst the qualified respondents than the other two groups. \\ The amount of variance in intention explained by TPB variables is less than in most other \\ studies for the unqualified and in-training groups. We suggest that TPB, although useful in the \\ vocational context, is less effective for the bigger and harder-to-implement decisions in life \\ than for smaller and easier to implement ones. We conclude that the absolute and relative \\ importance of some TPB variables varies with personal circumstances, and that proposed \\ extensions to TPB may not always be necessary.
}




\section{Introduction}

The Theory of Reasoned Action (Ajzen \& Fishbein, 1980), and its successor the Theory of Planned Behavior (TPB) (Ajzen, 1991) have been used extensively in theory and research on a wide range of human behaviors, particularly those associated with personal and community quality of life, such as waste recycling (e.g. Davies, Foxall \& Pallister, 2002; Chu \& Chiu, 2003), diet (e.g. Lien, Lytle \& Komro, 2002), exercise (e.g. Rhodes \& Courneya, 2003) and road safety (e.g. Elliott, Armitage \& Baughan, 2003). Comparatively little research has investigated the efficacy of TPB in the vocational realm. This is thankfully beginning to change (see Millar \& Shevlin, 2003; Van Hooft, Born, Taris \& van der Flier, 2004; Van Hooft, Born, Taris \& van der Flier, 2005), but much remains to be done in testing, extending and applying TPB to issues of career choice and development.

TPB (see Fig. 1) proposes that the proximal predictors of behavior are intention to perform that behavior, and the extent to which a person believes that the behavior in question is under his or her control (perceived behavioral control, or PBC). PBC influences behavior both directly and indirectly, through intention. In turn, intention is influenced by attitude, which is construed as a function of the sum total of a person's beliefs about the outcomes of the behavior in question, weighted by the valence and importance he or she attaches to those outcomes. Intention is also influenced by subjective norm (SN), which reflects a person's perceptions of significant others' evaluations of the behavior, weighted by the extent to which the person wishes to comply with the significant others' wishes. The three core elements of TPB hypothesised to predict intention (attitude, SN, and PBC) have been found in a metaanalysis (Armitage \& Conner, 2001) to have a multiple correlation with intention of around 0.6, the precise value depending a little on the intention measure used. According to Armitage and Conner, the mean correlation with intention of attitude is 0.49 , of SN 0.34 , and of PBC 0.43. The multiple correlation of the TPB variables (including intention) with behavior is 
around 0.5, again depending somewhat on the intention measure. Attitude tends to be the strongest predictor, PBC second, and SN the weakest, though as Ajzen (1991) has pointed out, this can be expected to vary between different contexts. Overall, then, TPB has undoubtedly been quite successful in explaining variance in intention and behavior (Sutton, 1998).

Insert Figure 1 about here

There have nevertheless been suggestions that it is necessary to extend TPB by adding further variables. The two most discussed of these are shown in Fig 1. The first is moral obligation (MO), or sense of duty. It has been suggested that some behavior is based on what a person believes to be right as well as what is attractive and feasible (Kurland, 1995). Many studies testing TPB have concerned behavior that might be perceived by some to have a moral dimension, but only relatively recently has this been taken into account. Several studies have found that MO adds to the prediction of intention and/or behavior over and above the core TPB variables (e.g. Parker, Manstead \& Stradling, 1995; Harland, Staats \& Wilke, 1999). However, in a large-scale longitudinal study, MO was not found to add significantly to the explanation of recycling behavior over and above the core TPB variables (Kaiser \& Scheuthle, 2003). The authors suggest that this may be because MO makes itself felt via attitude.

The second proposed extension to TPB concerns personal identity. It has been argued from both within TPB research (Sparks \& Guthrie, 1998; Terry, Hogg \& White, 1999) and outside (Haslam, Eggins \& Reynolds, 2003) that people’s personal and social identities are likely to be drivers of their behavior. Of course, a key proposition of much vocational theory and practice (Holland, 1997; Super, 1990) is that people seek to implement their sense of self 
through their occupational choices, so we might not be surprised to find that people's identity adds to the explanation of occupational intentions.

There is one further substantive issue regarding TPB that we wish to consider. This is the intention to perform alternative behaviors. Most research on TPB is nomothetic. That is, analyses are conducted between-persons. However, like the expectancy theory of motivation (Vroom, 1964), TPB is arguably a theory of behavioral choice where the focus is predicting what course of action a person will pursue from the repertoire available to him or her, rather than predicting whether person A is more likely to pursue that course of action than person B. Conner and Armitage (1998) amongst others have called for a more idiographic element to research on TPB. A person may express an intention to pursue a certain kind of work, but he or she may also express a stronger intention to pursue an alternative option. Given that many people have alternative careers potentially open to them, it is important to see whether the TPB predictors can explain occupational intentions after controlling for intention to pursue an alternative career. This is of course not a fully idiographic approach, but it acknowledges the availability of alternative courses of action.

The limited TPB research that has been conducted in the vocational field has broadly but not entirely consistently supported TPB. Norman and Bonnett (1995) found that attitude, SN and PBC explained 31\% of the variance in managers’ intentions to undertake a national vocational qualification, with each predictor making a significant individual contribution. Giles and Rea (1999) found that the same predictors explained around 70\% of the variance in intentions to pursue people or action-centered kinds of career, though SN did not make a unique contribution. Vincent, Peplau and Hill (1998) found that both gender-role attitudes and SN predicted women’s career intentions (PBC was not assessed). Van Hooft et al (2004) found that instrumental and affective attitudes, SN and PBC increased the explained variance in intention to search for jobs from .32 (explained by control variables) to .60, though PBC (in 
the form of self-efficacy) did not make a unique contribution. In a study of career exploration behavior, Millar and Shevlin (2003) found that only attitude added to the prediction of intention once past behavior was taken into account, though it was not clear how the TPB variables would have performed without past behavior. Van Breukelen, Van Der Vlist and Steensma (2004) found that TPB variables significantly predicted turnover intentions amongst Dutch naval professionals, but that other variables such as job satisfaction added to the variance explained over and above TPB variables.

We argue that published TPB research in vocational settings is limited in scope as well as volume. First, it does not test the extended version of TPB (i.e. including moral obligation and identity). Second, with the exception of the Van Breukelen et al (2004) study, it deals either with specific “small” everyday behaviors (e.g. career exploration, job search) or vague "big” behaviors (e.g. working in a certain kind of career). The combination of "big” and "specific" seems to us to be important because it reflects behavior that affects a person's life in major ways for a long time, and reflects the nature of decisions that careers often involve. Third, with the exception of the Millar and Shevlin study, past behavior is not taken into account. This could be important, not only because past behavior might reflect habitual patterns, but also because some past behaviors may create commitments in the form of "side bets" (H. S. Becker, 1960) and dissonance reduction (Vroom \& Deci, 1971) that affect a person’s evaluation of current options. Fourth, extant TPB research does not assess intention relative to alternative intentions. If we want to predict behavior in the vocational field, it seems to us important to take a person's alternatives into account.

\section{The Context of this Study}

In the study reported here, we test the TPB in the context of explaining the intentions of a large and diverse sample of UK adults to work for the UK's National Health Service (NHS) in 
one of three professions facing staffing shortages: nursing, physiotherapy and radiography. Consistent with our arguments above, we include identity and moral obligation as well as the core TPB variables, and we use both "raw" intention and intention after controlling for alternative intention.

We also test TPB amongst three groups who differ a lot in their circumstances. These differences offer the chance to test the generalisability of TPB in the vocational realm. The first group is people who are neither currently qualified nor undertaking qualification in the health profession they have in mind (we call these unqualified, though this refers only to the profession, they may have many other qualifications). These people have a long hard road ahead of them if they decide they want to work for the NHS as a qualified nurse, physiotherapist or radiographer. The second group is students in training. They vary from just started to nearly finished. They have made a clear commitment and often considerable sacrifices in order to undertake professional qualifications, and are likely to intend to work for the NHS at least for a time afterwards. Their training will include a lot of exposure to NHS workplaces. The final group consists of already fully qualified professionals. They may require some refresher training in order to work for the NHS, but this is not usually onerous. NHS employment is therefore a very realistic possibility for them, but they have nearly all chosen at some time to leave it. Their reasons for doing so and commitment to the decision may both be prominent in their minds.

Before specifying our hypotheses, we now describe key features of the NHS. There are two reasons for this. First, the NHS may be unfamiliar to many readers, and second because some of its features influences both the hypotheses we make and the interpretation of our findings.

Founded shortly after World War 2, the UK’s National Health Service nowadays employs about one million people out of a UK population of a little under 60 million. It has 
its own local and national management, but broad policy and funding are largely dictated by government. Subject to frequent reforms and reorganizations initiated by successive UK governments, the NHS has been opened up to more market forces and competition, both from within itself and from outside (Laing and Hogg, 2002). It is also working increasingly closely with private health-care providers. Nevertheless, it is still fundamentally a publicly funded service. It is used for some aspects of their health-care by nearly all the UK population, and for all health-care by the majority. Although some of its services are paid for by patients deemed able to afford it, most remain free at the point of use. This was a founding principle of the NHS (a statement of the principles and mission of the NHS in England can be found at http://www.nhs.uk/England/AboutTheNHS/CorePrinciples.cmsx).

The NHS is in the public eye all the time. Its effectiveness, funding and management are constantly in the UK news, and the subject of much political debate. It is much loved and appreciated for its benefits and as an expression of British national identity (Macpherson, 1998), but also criticised for its perceived shortcomings and failures, not least by some who work in it (Alexander and Smythe, 1996). There is also a significant private health sector in the UK, which includes some hospitals and other facilities, as well as many health professionals such as physiotherapists in their own private practices. People use private health facilities primarily to avoid NHS waiting lists, and/or because they perceive private facilities offer better quality.

The NHS is by far the UK's biggest employer of health-related staff. Furthermore, the NHS Plan (Department of Health, 2001) and subsequent policy statements commit the UK government to increase staff numbers in virtually all health-related professions. Achieving this will require highly effective policies for recruitment, retention and return (e.g. from other employment, or raising a family) (Buchan, 1999; Meadows, 2002). Currently, under-staffing is perceived to be a common problem (Audit Commission, 2002). Although perceived as 
rewarding in some important ways, NHS work tends to be seen as highly pressured and rather thankless, with insufficient time or resources to give patients as much individual attention as staff would like (Audit Commission, 2002).

Nearly all health professionals work in the NHS at some point in their career, especially during their training and when recently qualified. Many stay in the NHS for their whole career. However, employment in the private health sector or elsewhere is potentially available. Getting professionally qualified is academically demanding, with considerable demands in the training process, and (especially for physiotherapy) very high prior educational achievement required for entry. Some financial support is available to students from the government and NHS. However, financial costs in terms of loans and/or lost earnings are often considerable.

\section{Development of Hypotheses}

Most articles on TPB simply state that attitude, SN and PBC are expected to predict intention and/or behavior because that is what the theory specifies. However, as Ajzen (1991) points out, differences between contexts are likely to influence the strength of the predictors. So it is worth stating the logic that guides our hypothesising. In the hypotheses below, references to intention to work for the NHS include both "raw" intention and intention after controlling for intention to pursue a career alternative.

The nature of NHS work, particularly nursing, is quite visible to the public. Therefore people are likely to believe that they have the necessary information to make judgments about the outcomes of working for the NHS. This in turn should mean that their attitudes toward doing so are clear and perceived as relevant to decisions about whether to enter or re-renter such work. 
H1: Attitude will be significantly positively associated with intention to work for the NHS as a nurse, physiotherapist or radiographer, over and above the other elements of TPB.

Some researchers have suggested that subjective norm might be dropped from TPB due to its weak performance as a predictor of intention and behavior (Armitage and Conner, 2001). However, we expect SN to matter in this context. Because the NHS is in the public eye, people are likely to have opinions about it, including its suitability as an employer for their relatives and friends. Furthermore, the NHS is scarcely a taboo subject, so the opinions of significant others are likely to be known by individuals considering working for the NHS.

H2: Subjective norm will be significantly positively associated with intention to work for the NHS as a nurse, physiotherapist or radiographer, over and above the other elements of TPB.

We also expect PBC to predict intention. As indicated above, getting qualified and working for the NHS are widely seen as likely to tax one's personal resources. Also, although jobs as nurses, physiotherapists and radiographers are fairly prevalent, they are of course subject to competition.

H3: Perceived Behavioral Control will be significantly positively associated with intention to work for the NHS as a nurse, physiotherapist or radiographer, over and above the other elements of TPB.

We expect moral obligation (MO) to be of considerable importance in this context. Some people are likely to feel a sense of moral obligation to contribute to the common good by working for the NHS, and/or pay back government investment in one's training. This can 
plausibly be hypothesised to operate at least partly independently of the core elements of TPB because they are more instrumental and pragmatic.

H4: Moral obligation will be significantly positively associated with intention to work for the NHS as a nurse, physiotherapist or radiographer, over and above the other elements of TPB.

It is reasonable to expect that some aspects of identity are likely to find expression through the other variables mentioned above. For example, a person who considers him- or her-self to be a caring and socially responsible person might feel more moral obligation to work for the NHS than a person with a different identity. Nevertheless, notions of fit (or congruence) between person and work are so pervasive (Tinsley, 2000) that we might also expect identity to operate at least partly independently of these other factors.

H5: Identity as a person who would fit into the NHS will be significantly positively associated with intention to work for the NHS as a nurse, physiotherapist or radiographer, over and above the other elements of TPB.

Given the different circumstances of the three groups of respondents, what differences can we expect? In terms of mean differences, it is likely that the qualified group will be most negative about the NHS on several measures, because they have nearly all at some time chosen to leave it. It is likely that the unqualified group will show the lowest levels of PBC, because getting qualified is a long-term and challenging task. The in-training group is likely to have the strongest intention to work for the NHS because they are on the way to qualification and have likely decided that this is what they want to do. But our main interest is in whether the capacity of the components of TPB to explain variance in intention will vary significantly between the three groups. 
We predict that attitude will be a more powerful predictor for the qualified than for the unqualified. Because the qualified have nearly all worked for the NHS in their profession, some for a long time, they will have more reason than the other groups to be confident that their attitude is well-founded. In other words, their attitudes are likely to be more salient and certain than other groups' (Krosnick \& Petty, 1995), whether or not they are more extreme. We also expect PBC to matter more for those who are currently not professionally qualified than for those who are. The difficulties of the qualification process are likely to be substantial worries for some unqualified people: considerably more so than the prospect of refresher training for qualified people thinking of returning to the NHS or completing training for those who have already been selected for it and embarked upon it. Finally, we also expect MO to have a less strong relationship with intention in the qualified group than the other two. It is likely that whatever moral obligation the qualified group might have felt had been put aside when they decided not to work for the NHS, and therefore would not have an impact on their intention to work for the NHS in the future. Therefore, we hypothesise:

H6: Attitude will be more strongly related to intention in the qualified group than in the other two groups.

H7: $P B C$ will be more strongly related to intention in the unqualified group than in the other two groups.

H8: MO will be less strongly related to intention in the qualified group than in the other two groups.

\section{Method}

\subsection{Respondents and procedure}

The findings reported here are from a questionnaire administered in the second stage of a study commissioned by the UK government's Department of Health. The first stage consisted 
of group and individual interviews with a range of people (Authors, 2003a,b; 2004), and these were used along with other relevant literature to inform the content of the second stage questionnaire. In this questionnaire, respondents were asked to select one of the three professions, and complete the remainder of the questionnaire with that profession in mind. As well as the measures described below, there were a number of closed and open questions about specific perceptions of NHS employment, personal work preferences and demographic variables. Respondents were guaranteed confidentiality, and a prize draw with five prizes of $£ 100$ was used as an incentive to respond. The length of time available for the research and the requirements of the bodies with which we liaised, as well as UK data protection legislation, meant that we were not in a position to send reminders to non-respondents.

Respondents were recruited from several sources. The principal source was callers to the NHS Careers helpline who had given permission for their contact details to be used for follow-up purposes. A sample of 3650 callers during the previous two years who were recorded as having enquired about nursing, physiotherapy or radiography was constructed on our behalf by the company administering the database. The sample was stratified for age. People under-represented in the professions (i.e. ethnic minorities and males) were oversampled by including all callers from these groups during the most recent year. Questionnaires were mailed by the database administrators, with a covering letter endorsing the research from NHS Careers (the organization responsible for the helpline), and a pre-paid reply envelope addressed to us (this arrangement also applies to the other data-collection sources below). In total, 715 completed questionnaires were returned, representing a response rate from this source of $19.6 \%$.

Most of the NHS Careers respondents, though not all, were in our unqualified group, and were interested in nursing. We therefore used additional sources to tap qualified and in process of becoming qualified respondents, especially in physiotherapy and radiography. We 
enlisted the help of two professional associations - the Society of Chartered Physiotherapists (CSP) and the Society of Radiographers (SoR). They forwarded questionnaires and covering letters (CSP 512, SoR 212) on our behalf to members who either worked as assistants or were fully qualified and not currently employed by the NHS. In total we received 153 (30\%) completed questionnaires from the CSP mailing, and 55 from the SoR mailing (26\%). Two employment agencies with qualified physiotherapists and/or radiographers on their books also distributed questionnaires and covering letters on our behalf. In total 200 were sent out and 82 completed questionnaires were returned, for a response rate of $41 \%$. Finally, we used our preexisting contacts with university schools of nursing, physiotherapy and radiography to send questionnaires and covering letters to their students. A total of 395 were sent out and 170 completed questionnaires were received back, for a response rate of $43 \%$.

Overall, then, we received 1175 responses from 4969 questionnaires sent out, for a response rate of $23.6 \%$. We also received around 50 marked "not known at this address" or similar (we did not record the exact number) and undoubtedly some others also failed to reach their intended recipients due to out of date addresses. The response rate as a percentage of those who actually received a questionnaire is therefore certainly higher than $23.6 \%$, but we do not know how much higher. For the purposes of this paper, the following questionnaires were excluded from analysis: qualified professionals currently working for the NHS $(\mathrm{N}=43)$; respondents who (in spite of our instructions) completed the questionnaire with a profession in mind that was not one of the three of interest to us $(\mathrm{N}=76)$; and respondents with missing data on one or more variables of central interest to us in this paper $(\mathrm{N}=78)$, leaving a total of 978. These comprised 507 unqualified, 244 in training and 227 qualified.

Demographic and other background information was collected on the questionnaire. This included age (in years), marital status (single/not living with partner or married/living with partner), gender, day to day responsibility for childcare (yes/no, and if yes, further details), 
ethnic background (the 17-group categorisation used by UK government agencies), whether any friends or family worked in the profession the respondent had in mind (two separate questions, yes/no), and whether the respondent had worked for the NHS in a previous job (yes/no). Descriptive data for the respondents are shown in Table 1. Although they did not differ greatly in gender and ethnic composition, there were some differences between the three groups. The in-training respondents were somewhat younger than the others on average, and less likely to be married or have children. Members of the qualified group were on average older than the other two groups, by far the most likely to have friends in the profession, and to have worked for the NHS in a previous job. They were also more likely than members of the other groups to have completed their questionnaire with radiography in mind. A much higher proportion of the unqualified group than the other two chose nursing.

Table 1 about here

\subsection{Measures for testing TPB}

Intention was assessed with a 3-item scale similar to that used in many TPB studies. Respondents were asked to indicate on a 7-point semantic differential scale whether working for the NHS as a qualified member of the profession they had in mind was Unlikely - Likely. Also on a 7-point scale, they are asked to indicate their level of agreement or disagreement to statements planning and intending to work for the NHS as a qualified member of that profession. Alpha reliability coefficient was 0.96 .

Attitude was measured with four items. Three used a 7-point semantic differential format, where respondents indicated whether they thought working for the NHS as a qualified member of the profession was Enjoyable - Unenjoyable; Wise - Unwise (reverse-scored); and Bad - Good. The fourth item asked respondents to indicate their agreement or 
disagreement on a 7-point scale to a statement that their attitude to working for the NHS in the profession was positive. The alpha reliability coefficient for this scale was 0.78 .

Subjective norm (SN) was assessed with two items, each with as 7-point Strongly Agree - Strongly Disagree scale: The items concerned whether family and friends would approve of the respondent working for the NHS in the profession, and whether family and friends would be proud if the respondent did so. Alpha reliability for this scale was 0.79 . Although we also included items about motivation to comply with the wishes of friends and family, in common with most TPB research, we did not incorporate these into our measure of SN. French and Hankins (2003) amongst others have pointed out the perils of using multiplicative terms (i.e. in this case others' opinions x motivation to comply) in TPB research. The reliability of a product term is likely to be low, and there are controversies about whether or not to center response scales around zero, thus allowing negative scores (Trafimow \& Finlay, 2002). In any case there is evidence that simply using expected outcomes of behavior produces better prediction than weighting the outcomes by importance (Gagne and Godin, 2000).

There have also been debates about the nature and measurement of perceived behavioral control PBC. Armitage and Conner (2001) distinguish between measures based on selfefficacy, the perceived ease or difficulty of performing the behavior, and perceived control over behavior. We decided that in this context it would make most sense to respondents to ask about the perceived ease or difficulty of performing the behavior. Accordingly, we devised two items, one asking about the respondent's perceived confidence that he or she could work for the NHS as a qualified professional if (s)he wanted to, and the other about the perceived difficulty of getting an NHS job as a qualified professional (reverse scored). Both items had 7-point Strongly Agree - Strongly Disagree response scales. Unfortunately the alpha reliability coefficient for this scale was only 0.42 . We therefore decided to use the two items as separate single-item indicators of (perhaps different aspects of) PBC. 
Identity was assessed with two items, both using a 7-point Strongly Agree - Strongly Disagree response scale. One item concerned belief in the principles of the NHS, and the other reflected the perceived fit between self and NHS culture. The alpha coefficient for this scale was 0.63 - rather low, but we decided this was high enough to retain as a two-item scale.

Moral obligation was assessed with a single item "I would feel guilty if I did not work for the NHS as a qualified member of staff” (there were frequent reminders throughout the questionnaire that "qualified member of staff” signified qualified in the profession they had chosen at the start of the questionnaire). Again, responses were recorded on a 7-point Strongly Agree - Strongly Disagree scale.

Alternative career. We asked respondents to indicate whether they had an alternative career in mind (yes/no) and if so, what it was (open-ended response), and whether they were currently working in it (yes/no). A short series of questions about that alternative followed. One of these was "I intend to work in my alternative career” (7-point Strongly Agree Strongly Disagree scale) - an exact parallel to one of the items in the intention scale described above. Unfortunately, space restrictions precluded repeating all four items.

\section{Results}

Descriptive statistics are shown in Table 2. For the sample as a whole, mean scores for intention, attitude, SN, PBC and identity were all on the favorable side of the mean from the NHS's point of view. However, attitude, SN and (especially) intention scores for the qualified group were lower than for the other two groups. This was as expected, for the reasons outlined earlier. Mean scores for intention to work in the alternative career were somewhat above the midpoint of the scale, especially for the qualified respondents (many of whom were working in that alternative), whilst scores for MO were below the midpoint, again especially 
for the qualified respondents. As expected, PBC was lower on average for the unqualified group than the other two, but nevertheless quite high. It seems that the unqualified group generally believed they could work for the NHS as a qualified professional if they wanted to. They also tended to think they were the kind of person who would feel comfortable in the NHS, and perhaps surprisingly rather more so than the in-training group.

In line with much other TPB research, attitude showed the highest correlations with intention, though this was much more notably the case for the qualified group than the others. Contrary to some other TPB research, SN also correlated quite strongly with intention, and so did MO. Identity was a strong correlate of intention for the in-training and qualified groups, but not the unqualified. The PBC item reflecting confidence correlated more highly with intention than the item reflecting perceived difficulty. The PBC confidence item also correlated much more strongly with identity than the PBC difficulty item did. Intention to work for the NHS was moderately negatively correlated with intention to work in the alternative career. In general, correlations between the other TPB variables and intention to work in the alternative career were low to moderate, and in the expected directions - that is, variables that correlated positively with intention to work for the NHS correlated negatively with the alternative career intention, and vice versa. Finally, intercorrelations of predictor variables were moderate, and variance inflation statistics in regression analyses (see below) revealed no multicollinearity problems.

Tables 2 and 3 about here

Table 3 shows results of five multiple regression analyses, testing for the explanatory power of the TPB variables for each of the three groups, once without controlling for alternative career intentions, and (for the two groups with sufficient numbers specifying an 
alternative career) once with that control. Few members of the in-training group specified an alternative career, so regressions controlling for alternative career were not possible for them. In each case we also used dummy variables to control for the profession respondents had in mind when completing the questionnaire. This was done in order to take out any variance in intention purely attributable to the profession the respondent happened to choose. Only the choice of nursing amongst unqualified respondents without controlling for alternative career was significantly related to intention (see Table 3). We considered also controlling for other demographic variables shown in Table 1, but decided not to because (i) not controlling for them does not threaten the validity of our theoretical tests, and (ii) differences in demographic profiles between our three groups (e.g. qualified people are older on average) reflect the naturally occurring differences between the groups, and to control for them would be to eliminate part of what interests us in hypotheses 6,7 and 8.

Table 3 shows that attitude was a highly significant predictor of intention over and above the other TPB variables, thus providing strong support for $\mathrm{H} 1$ across all three groups, and whether or not alternative career intentions were controlled for. In every case, the beta weight for attitude was stronger than for any other TPB variable, particularly for the qualified group.

$\mathrm{H} 2$, that subjective norm would be related to intention, also received considerable support. The beta weights for SN were statistically significant at $p<.01$ or better for both the qualified and unqualified groups with and without controlling for alternative career intentions. However, SN was not significantly related to intention in the in-training group.

H3, that PBC would be significantly associated with intention, received patchy support. Both PBC items were significant predictors of intention in the expected direction in the unqualified group when alternative career was not controlled for, but not when it was. The confidence PBC item was associated with intention in the qualified group, particularly when alternative career was controlled for, but the difficulty PBC item was not, though it came 
close to significance when alternative career was not controlled for. As with SN, PBC was not a significant predictor of intention amongst the in-training group.

H4 received only patchy support. MO was statistically significantly associated with intention in the unqualified and in-training groups (in both cases without control for alternative career intentions), but not the qualified group.

H5 also received only limited support. Identity added significantly to the variance explained in intention only in the in-training group - that is, in one analysis out of five.

Two-tailed tests were used in all the statistical significance testing reported above. Given the nature of the hypotheses, there is a good case for using one-tailed tests. Our decision was made for the sake of consistency with other studies, and because identity showed some beta weights in the opposite direction to that predicted. Given that the raw correlations were generally in the expected direction, this is almost certainly due to suppressor effects. Use of one-tailed significance would have meant that the PBC difficulty item became significant in four of the five analyses shown in Table 3.

The proportion of variance in intentions explained by the TPB variables collectively was highly significant in every case. On the other hand, that proportion was lower than in most TPB studies, largely due to the unqualified group.

H6 stated that attitude would explain a greater proportion of the variance in intention in the qualified group than in the other two. Using the test for significance of difference between unstandardised regression coefficients (Bs) specified in Cohen and Cohen (1983, p111), we compared the B of 0.79 for attitude as a predictor of intention in the qualified group (without controlling for alternative career) with the B of 0.37 for the unqualified group. The difference was statistically significant $(z=3.22, p<.01)$. The $\mathrm{B}$ for the qualified group was also statistically significantly different from the B for the in-training group (.25) $(z=4.15, p<$ .001), again without controlling for alternative career intention. However, when alternative 
career intention was included in the regression, the B for attitude of .75 in the qualified group was non-significantly different from the B of .49 for the unqualified group ( $z=1.35$, NS). This non-significant result was largely due to the high standard error of attitude in the qualified group, which in turn was partly the product of the small sample size of unqualified people who specified an alternative career. Overall then, Hypothesis 6 therefore received strong support when alternative career was not controlled for.

In $\mathrm{H7}$ we predicted that PBC would be a significantly stronger predictor of intention in the unqualified group than the other two. This hypothesis was not supported. Taking first the analyses without controlling for alternative career intentions, although the beta weights shown in Table 3 for the two PBC items are more statistically significant in the unqualified group than the other two, the differences in absolute magnitude of Bs and beta weights are small, and none of the four comparisons approached statistical significance. Furthermore, when alternative career intention was controlled for, the B in the unqualified group for the PBC confidence item was statistically significantly lower than in the qualified group $(z=2.44, p<$ $.05)$.

Finally, H8 predicted that in the qualified group MO would have a less strong relationship with intention than in the other two groups. The beta weights shown in Table 3 show that MO was significantly associated with intention in the unqualified and in-training groups, but not in the qualified group. However, the differences in absolute values were small, and even more so for the B values. None of the differences were statistically significant. H8 was therefore not supported.

\section{Discussion}

We examined the capacity of the extended TPB to predict intention to work for the UK's National Health Service as a nurse, physiotherapist or radiographer amongst with three 
groups: those not professionally qualified, those in training and those qualified but not currently working for the NHS. Taken as a set, the TPB variables always accounted for highly significant proportions of the variance in intention. However, in none of the five regression analyses did each of the extended TPB variables account for significant variance in intention. Only attitude was a significant predictor in all five analyses, which supports its dominant role found in most other studies. It was significantly more strongly associated with intention in the qualified group than the other two. SN was significant in four analyses, which is a stronger performance than often found in other work. PBC (confidence) was a significant predictor of intention in three of the five analyses, $\mathrm{MO}$ in two, identity in one, and PBC (difficult) in one. In the unqualified group, the TPB variables as a whole accounted for much less variance in intentions than in most TPB studies (c.f. Armitage and Conner, 2001). The proportion of variance accounted for was somewhat less than the TPB research norm in the in-training group, and about comparable in the qualified group. Controlling for intention to pursue an alternative career reduced the contribution of PBC, MO and identity amongst unqualified respondents, but made less difference amongst the qualified group.

We conclude from this that the TPB has utility in this context but could benefit considerably from further development. In terms of variance in intention explained, it was most effective amongst the qualified respondents, for whom working for the NHS would be fairly readily achievable. It is notable also that attitude was a particularly powerful predictor of intention in the qualified group. This is likely because members of this group nearly all had prior experience of NHS work which gave them confidence that their attitude was wellfounded, and because most had made a decision to leave the NHS in favor of alternatives - a decision which carrying considerable behavioral commitment which also strengthened their attitude. After controlling for target profession, in the qualified group the extended TPB variables explained an additional 38\% of the variance in intentions, compared with only about 
8\% amongst the unqualified. Bearing in mind that much other TPB research concerns relatively easily implemented behaviors, it may be that TPB is less adequate for the more complex and challenging aspects of life.

The unqualified group was likely to be the most varied in terms of personal circumstances and therefore subject to the widest range of factors impinging on intentions. Also, for this group the intention to work in the NHS as a qualified nurse, physiotherapist or radiographer would be more difficult to implement than for respondents in the other two groups. But even so, if TPB was truly effective, one could argue that those factors should find expression through the TPB variables. For example the range of social influences experienced by the unqualified respondents should be reflected in SN, and the potential difficulties of professional training and job-seeking should be expressed via PBC.

We suspect that perceptions of external constraints may partly explain why only a low proportion of the variance in intentions of the unqualified group was explained. For the unqualified group in particular, our PBC items may not have captured fully the potential barriers to qualification such as the financial cost and time commitment, and the need (for some respondents) to obtain further educational qualifications before they could be considered for training (even so, the mean intention score of 5.01 presumably means that most did not see these as insurmountable). Four questions about external constraints were included in the questionnaire. They asked whether respondents would be put off working for the NHS as a qualified member of staff by: not currently having the qualifications to be accepted for training; the length of time it takes to become a qualified healthcare professional; the financial cost of training, and the lack of access to refresher training. A very broad view of PBC might even permit their inclusion in a PBC measure, though this would take the construct outside any of the three approaches identified by Armitage and Conner (2001). However, we view them as external constraints on action and/or indirect statements of personal priorities which 
may have some impact on PBC and perhaps other TPB variables rather than being PBC per se.

Supplementary analyses showed that the four external constraints questions, when added as a scale (alpha $=.77$ ) to the regression equation for the unqualified group shown in the left hand column of Table 3, added a highly statistically significant $5.4 \%$ to the proportion of variance in intention explained, and took the overall adjusted $\mathrm{R}^{2}$ up to .30. Furthermore, this external constraints measure added another $5.6 \%$ to the variance in intention explained when alternative career intention was included in the regression analysis (the second column in Table 3). We suggest that TPB research should take more explicit account of perceptions of external constraints, especially of course where they are likely to be relevant to the implementation of behavior, as in this case. We think this may be a weak spot in TPB: a person may believe he or she can accomplish the behavior if (s)he wants to, and have a positive attitude to it, but still not wish to overcome hurdles to perform it.

In contrast with some other TPB research, but consistent with van Hooft et al's (2004) analysis of job search intentions (especially for ethnic minority respondents), it appears that subjective norm plays a significant role in occupational intentions. SN is clearly not a weak link in TPB in this context, at least for two of the three groups. This emphasises the partially social or "community” (Law, 1981) nature of occupational decisions, and the often complex social influences that are relevant to a wide range of career phenomena, such as the way people evaluate their career success (Heslin, 2005) and cope with undesired career transitions (Ebberwein, Krieshok, Ulben, \& Prosser, 2004). Occupational decisions usually have implications for other people close to the decision-maker, so in that sense it is appropriate to take their views and interests into account. These people may also have experience relevant to that decision, and also firm opinions about it. As indicated in our discussion of the NHS, both 
these conditions are likely to be met in this case, because the NHS is at the center of UK public life.

The results for moral obligation (MO) provide some limited support for its importance in this context. Our equivocal results plus the conflicting findings in other work (e.g. Harland et al, 1999; Kaiser \& Scheuthle, 2003) suggest that the jury is still out on the added value of MO. When alternative career intention was not included in the analyses, MO accounted for significant amounts of variance in intention for the unqualified and in-training groups, but not for the qualified. This last group had almost all worked for the NHS in the past, and chosen to leave. In making that choice, they likely either reduced any sense of moral obligation they felt, or decided to set aside that sense of obligation in favor of other (perhaps more instrumental) considerations. On the other hand, it is dangerous to draw contrasts between the three groups because the differences in regression weights were non-significant. Nevertheless, the significant effect of MO for two of the groups serves as a reminder that for some people in some contexts, the notion of calling, vocation (Hall, 2005), or dedication to a cause (Schein, 1996) may influence intention.

The findings for identity suggest that those who argue that it is reflected in other TPB variables, especially attitude, may be correct. The correlations in Table 2 show quite strong relationships between identity and intention, but in only one of the five regressions does identity make a unique contribution (see Table 3). Supplementary regression analyses (not shown) indicated that, in the unqualified and qualified groups, identity lost its significant relationship with intention when attitude was entered into the equation. Nevertheless, identity was significantly related to intention amongst the in-training respondents, which suggests that it cannot yet be ruled out as a valuable addition to TPB.

Indeed, taken as a whole, the findings are rather different for the in-training group than the other two. For them, but not the others, neither PBC nor SN were significantly related to 
intention, but identity was. Bearing in mind that this group had probably invested quite a lot of material and personal resources (such as their sense of identity) in their professional training, it is likely that they were acutely aware of their behavioral commitment to that course of action (H. S. Becker, 1960; T. E. Becker, Billings, Eveleth, \& Gilbert, 1996; van Dam, 2005). Consistent with this, whilst their intention to work for the NHS in their profession was higher than the unqualified respondents, their attitudes were somewhat less positive. A tentative interpretation of this (and one that would ring true to many observers familiar with the NHS) is that the in-training group had begun to experience some of the negative aspects of NHS work via their work placements, but were for the time being more or less committed to working for it (newly qualified nurses, physiotherapists and radiographers nearly always need the experience offered by the NHS before being able to move elsewhere). The extent to which resources were being invested in them may also have been very salient, which could have enhanced both their sense of moral obligation and its connection with intention. The lack of significance of SN amongst the in-training group could be because fewer of this group than the other two were married or living with a partner, and this could have reduced the social pressure upon them. This tentative explanation is consistent with recent work by Van Hooft, Born, Taris and van der Flier (2005), who found that social pressure was a less strong predictor of job search behavior amongst single people than married or cohabiting people.

Our findings suggest that assessing intention net of alternative intention leaves the capacity of attitude and subjective norm to account for intention unscathed, or even strengthened. We interpret this as strong evidence for the importance of attitude and SN, which are both core TPB constructs. They help to explain the extent to which a person intends to pursue a course of action over and above a realistic alternative. We anticipate, but cannot demonstrate, that this will link more closely with actual behavior than "raw" intention would. 
The effect of controlling for alternative career intentions was more complex for the other TPB variables. Amongst unqualified people, PBC and moral obligation lost their significant relationships with intention when alternative career intention was controlled for. On the other hand, amongst the qualified respondents, the PBC confidence item became a stronger predictor of intention to work for the NHS when the alternative intention was controlled for. Explanations for this difference are necessarily speculative. One reason might be that in certain circumstances, PBC and MO regarding one course of action may influence alternative intentions at least as much as intention to perform the behavior in question. So, for the unqualified people, lack of PBC regarding working for the NHS as a qualified professional could lead them to intend to enter an alternative career more than it put them off working for the NHS. However, this does not explain why amongst the qualified people the PBC confidence item became a stronger predictor of intention when alternative career intention was included in the analysis.

\section{Future Research and Limitations of this Study}

We suggest that the development of our understanding of both TPB and occupational intentions could be enhanced by further TPB research in the vocational field. Occupational decisions are often major and salient choice points in a person's life, arguably usually more so than (for example) recycling waste, maintaining a diet, or engaging in career exploration, though we do not wish to underplay the importance of those things. Furthermore, the implementation of occupational choices often requires considerable sustained effort, and complex sets of actions. This is therefore an area that offers stringent tests of TPB, and we believe that vocational psychologists should be more concerned with not only utilising TPB, but also testing and extending it, as we have attempted to do here. As well as further investigation of extensions to TPB, we believe that fruitful lines of enquiry will concern the 
roles of (i) differences between individuals and groups in ease of implementation of occupational decisions, as well as prior behavioural commitment to alternatives, and (ii) perception of external constraints which may operate independently of PBC.

This study is of course limited by its cross-sectional design and absence of a measure of actual behavior (the contractual terms of our project unfortunately precluded follow-up of individuals to see whether they implemented their intentions). Furthermore, some of our measures were single item. In the case of PBC this was because the items did not scale as intended; for the other single-item variables it was a case of not over-burdening respondents given the other things we wanted to ask them about. Some other studies in the vocational realm (e.g. Giles \& Rea, 1999; Norman \& Bonnett, 1995) and outside it (e.g. Sparks \& Guthrie, 1998; Terry et al, 1999) have also made some use of single-item measures, but it is clearly not ideal. Our response rate from the NHS Careers database was less than we would have wanted, though given the likely changes of address and only passing interest of some of those who contacted NHS Careers, it is not surprising. Our response rate of $19.6 \%$ from the NHS Careers database and 23.6\% overall compares fairly well with other studies of populations over which researchers have little influence. Recent examples include Van Hooft et al’s (2004) 14.3\% in their TPB study of employment agency staff, and with Van Hooft, Born, Taris, van der Flier and Blonk’s (2005) 19.3\% in their study of job search behavior amongst unemployed people.

Despite the limitations, we believe we have taken TPB into new ground and in doing so we have found reason to question its adequacy in this context, and reason to think that TPB operates somewhat differently, and with different levels of overall effectiveness, for different groups. 


\section{References}

Ajzen, I. (1991). The theory of planned behavior. Organizational Behavior and Human Decision Processes, 50, 179-211.

Ajzen, I., \& Fishbein, M. (1980). Understanding attitudes and predicting social behaviour. Englewood Cliffs, NJ USA: Prentice-Hall.

Alexander, M., and Smythe, M. (1996). Professions allied to medicine: A study of five professions by following people identified as qualified in the 1991 census. London, UK: Office of National Statistics

Armitage, C. J. and Conner, M. (2001). Efficacy of the theory of planned behavior: A meta-analytic review. British Journal of Social Psychology, 40, 471-499.

Audit Commission (200). Recruitment and retention: A public service workforce for the twenty-first century. London, UK: Audit Commission.

Authors (2003a) Reference removed to maintain anonymity during review.

Authors (2003b) Reference removed to maintain anonymity during review.

Authors (2004) Reference removed to maintain anonymity during review.

Becker, H. S. (1960). Notes on the concept of commitment. American Journal of Sociology, 66, 32-40.

Becker, T. E., Billings, R. S., Eveleth, D. M., \& Gilbert, N. L. (1996). Foci and bases of employee commitment: Implications for job performance. Academy of Management Journal, 39, 464-482.

Buchan, J. (1999). The greying of the United Kingdom nursing workforce: Implications for employment policy and practice. Journal of Advanced Nursing, 30, 818-826.

Chu, P. Y., \& Chiu, J. F. (2003). Factors influencing household waste recycling behavior: Test of an integrated model. Journal of Applied Social Psychology, 33, 604-626. 
Cohen, J., \& Cohen, P. (1983). Applied multiple regression/correlation analysis for the behavioral sciences. $2^{\text {nd }}$ Ed. Hillsdale, NJ, USA: Erlbaum.

Conner, M., \& Armitage, C. J. (1998). Extending the theory of planned behavior: A review and avenues for further research. Journal of Applied Social Psychology, 28, 14301464.

Davies, J., Foxall, G. R., \& Pallister, J. (2002). Beyond the intention - behaviour mythology: An integrated model of recycling. Marketing Theory, 2, 29-113.

Department of Health (2001). Investment and reform in NHS staff? Taking forward the NHS Plan. London, UK: Department of Health.

Ebberwein, C. A., Krieshok, T. S., Ulben, J. C., \& Prosser, E. C. (2004). Voices in transition: Lessons on career adaptability. Career Development Quarterly, 52, 292-308.

Elliott, M. A., Armitage, C. J., \& Baughan, C. J. (2003). Drivers’ compliance with speed limits: An application of the theory of planned behavior. Journal of Applied Psychology, 88, 964-972.

French, D. P., \& Hankins, M. (2003). The expectancy - value muddle in the theory of planned behaviour - and some proposed solutions. British Journal of Health Psychology, 8, 37-55.

Gagne, C., \& Godin, G. (2000). The theory of planned behavior: Some measurement issues concerning belief-based variables. Journal of Applied Social Psychology, 30, 21732193.

Giles, M., \& Rea, A. (1999). Career self-efficacy: An application of the theory of planned behaviour. Journal of Occupational and Organizational Psychology, 72, 393-398.

Hall, D. T. (2005). Psychological success: When the career is a calling. Journal of Organizational Behavior, 26, 155-176. 
Harland, P., Staats, H., and Wilke, H. A. M. (1999) Explaining pro-environmental intention and behavior by personal norms and the theory of planned behavior. Journal of Applied Social Psychology, 29, 2505-2528.

Haslam, S. A,, Eggins, R. A., \& Reynolds, K.J. (2003). The ASPIRe model: Actualizing social and personal identity resources to enhance organizational outcomes. Journal of Occupational and Organizational Psychology, 76, 83-113.

Heslin, P. A. (2005). Conceptualizing and evaluating career success. Journal of Organizational Behavior, 26, 113-136.

Holland, J. L. (1997) Making Vocational Choices $3^{\text {rd }}$ Ed. Englewood Cliffs: Prentice Hall Kaiser, F. G. \& Scheuthle, H. (2003). Two challenges to a moral extension of the theory of planned behavior: Moral norms and just world beliefs in conservationism. Personality and Individual Differences, 33, 1033-1048.

Krosnick, J. A., \& Petty, R. E. (1995). Attitude strength: An overview. In R. E. Petty \& J. A. Krosnick (Eds.), Attitude strength: Antecedents and consequences (pp. 1-24). Mahwah, NJ, USA: Erlbaum.

Kurland, N. B. (1995). Ethical intentions and the theories of reasoned action and planned behavior. Journal of Applied Social Psychology, 25, 297-313.

Laing, A., \& Hogg, G. (2002). Political exhortation, patient expectations, and professional execution: Perspectives on the consumerization of health care. British Journal of Management, 13, 173-188.

Law, B. (1981). Community interaction: A “mid-range” focus for theories of career development in young adults. British Journal of Guidance and Counselling, 9, 142-158.

Lien, N., Lytle, L. A., \& Komro, K. A. (2002). Applying theory of planned behavior to fruit and vegetable consumption of young adolescents. American Journal of Health Promotion, 16, 189-197. 
Macpherson, G. (1998) Our NHS: A celebration of 50 years. London, UK: BMJ Books.

Meadows, S. (2002). Great to be grey: How can the NHS recruit and retain more older staff? London, UK: King’s Fund

Millar, R., and Shevlin, M. (2003). Predicting career information-seeking behavior of school pupils using the theory of planned behavior. Journal of Vocational Behavior, 62, 2642.

Norman, P., \& Bonnett, C. (1995). Managers’ intentions to be assessed for national vocational qualifications: An application of the theory of planned behavior. Social Behavior and Personality, 23, 59-68.

Parker, D., Manstead, A. S. R., \& Stradling, S. (1995). Extending the theory of planned behaviour: The role of personal norm. British Journal of Social Psychology, 34, 127-137.

Rhodes, R. E., \& Courneya, K. S. (2003). Investigating multiple components of attitude, subjective norm, and perceived control: An examination of the theory of planned behaviour in the exercise domain. British Journal of Social Psychology, 42, 129-146.

Schein, E. H. (1996). Career anchors revisited: Implications for career development in the $21^{\text {st }}$ century. Academy of Management Executive, 10, 80-88.

Sparks P., \& Guthrie, C. A. (1998) Self-identity and the theory of planned behavior: A useful addition or an unhelpful artifice? Journal of Applied Social Psychology, 28, 13931410.

Super, D. E. (1990). Career and life development. In Brown, D., and Brooks, L. (eds.) Career Choice and Development $2^{\text {nd }}$ ed. San Francisco: Jossey-Bass.

Sutton, S. (1998). Explaining and predicting intentions and behaviour: How well are we doing? Journal of Applied Social Psychology, 28, 1318-1339. 
Terry, D. J., Hogg, M. A., \& White, K. M. (1999). The theory of planned behaviour: Self-identity, social identity, and group norms. British Journal of Social Psychology, 38, 225244.

Tinsley, H. E. A. (2000). The congruence myth revisited. Journal of Vocational Behavior, 56, 405-423.

Trafimow, D., \& Finlay, K. E. (2002). The prediction of attitudes from beliefs and evaluations: The logic of the double negative. British Journal of Social Psychology, 41, 7786.

Van Breukelen, W., Van der Vlist, R., \& Steensma, H. (2004). Voluntary employee turnover: Combining variables from the "traditional" turnover literature with the theory of planned behavior. Journal of Organizational Behavior, 25, 893-914.

Van Dam, K. (2005). Employee attitudes toward job changes: An application and extension of Rusbult and Farrell's investment model. Journal of Occupational and Organizational Psychology, 78, 253-272.

Van Hooft, E. A. J., Born, M. P., Taris, T. W., \& van der Flier, H. (2004). Job search and the theory of planned behavior: Minority-majority group differences in the Netherlands. Journal of Vocational Behavior, 65, 366-399.

Van Hooft, E. A. J., Born, M Ph., Taris, T. W., \& van der Flier, H. (2005). Predictors and outcomes of job search behavior: The moderating effects of gender and family situation. Journal of Vocational Behavior, 67, 133-152.

Van Hooft, E. A. J., Born, M Ph., Taris, T. W., van der Flier, H., \& Blonk, R. W. B. (2005). Bridging the gap between intentions and behavior: Implementation intentions, action control, and procrastination. Journal of Vocational Behavior, 66, 238-256. 
Vincent, P. C., Peplau, L. A., \& Hill, C. T. (1998). A longitudinal application of the theory of reasoned action to women's career behavior. Journal of Applied Social Psychology, 28, 761-778.

Vroom, V. H. (1964). Work and Motivation. New York: John Wiley.

Vroom, V. H., \& Deci, E. L. (1971). The stability of post-decision dissonance: Follow-up study of job attitudes of business school graduates. Organizational Behavior and Human Performance, 6, 36-49. 
Table 1: Characteristics of the Respondents

\begin{tabular}{|c|c|c|c|c|}
\hline & $\begin{array}{c}\text { All } \\
\text { Respondents } \\
(\mathbf{N}=978)\end{array}$ & $\begin{array}{l}\text { Unqualified } \\
(\mathbf{N}=507)\end{array}$ & $\begin{array}{c}\text { In Training } \\
(\mathrm{N}=244)\end{array}$ & $\begin{array}{c}\text { Qualified } \\
(\mathrm{N}=227)\end{array}$ \\
\hline Mean age (SD) & $29.6(10.7)$ & $28.2(10.2)$ & $24.8(7.2)$ & $38.3(10.1)$ \\
\hline$\%$ male & 13 & 13 & 12 & 15 \\
\hline \% ethnic minority & 8 & 9 & 8 & 6 \\
\hline \% with dependent children & 41 & 46 & 24 & 48 \\
\hline $\begin{array}{l}\text { \% married or living with } \\
\text { partner }\end{array}$ & 47 & 49 & 23 & 68 \\
\hline \multicolumn{5}{|l|}{ Profession of interest (\%) } \\
\hline Nursing & 58 & 78 & 48 & 22 \\
\hline Physiotherapy & 30 & 16 & 47 & 45 \\
\hline Radiography & 12 & 6 & 5 & 33 \\
\hline \% with friends in profession & 60 & 49 & 55 & 93 \\
\hline \% with family in profession & 22 & 25 & 21 & 17 \\
\hline$\%$ working for NHS now ${ }^{\mathrm{a}}$ & 12 & $23^{\mathrm{a}}$ & $0^{b}$ & 0 \\
\hline $\begin{array}{l}\text { \% worked for NHS in a } \\
\text { previous job }\end{array}$ & 34 & $16^{\mathrm{a}}$ & $17^{\mathrm{a}}$ & 92 \\
\hline
\end{tabular}

a. But not as a qualified nurse, physiotherapist or radiographer

b. But nearly all had experience of NHS work as part of their training for professional qualification. 
Table 2: Means, Standard Deviations and Intercorrelations of Key Variables

\begin{tabular}{|c|c|c|c|c|c|c|c|c|c|}
\hline & & 1 & 2 & 3 & 4 & 5 & 6 & 7 & 8 \\
\hline 1 & Intention & $\begin{array}{l}5.01(1.92) \\
5.09(1.74) \\
6.24(1.13) \\
3.50(1.98)\end{array}$ & & & & & & & \\
\hline 2 & Attitude & $\begin{array}{l}.50 \\
.34 \\
.39 \\
.59 \\
\end{array}$ & $\begin{array}{l}5.23(1.24) \\
5.70(1.03) \\
5.30(0.98) \\
4.12(1.23)\end{array}$ & & & & & & \\
\hline 3 & Subjective Norm & $\begin{array}{l}.39 \\
.31 \\
.25 \\
.37\end{array}$ & $\begin{array}{l}.49 \\
.34 \\
.37 \\
.41\end{array}$ & $\begin{array}{l}5.21(1.42) \\
5.62(1.30) \\
5.28(1.18) \\
4.22(1.43)\end{array}$ & & & & & \\
\hline 4 & $\begin{array}{l}\text { Perceived Behavioral } \\
\text { Control (Confident) }\end{array}$ & $\begin{array}{l}.22 \\
.24 \\
.30 \\
.26\end{array}$ & $\begin{array}{l}.22 \\
.33 \\
.32 \\
.19\end{array}$ & $\begin{array}{c}.06 \\
.15 \\
.18 \\
-.09\end{array}$ & $\begin{array}{l}5.88(1.54) \\
5.76(1.59) \\
6.01(1.31) \\
6.01(1.63)\end{array}$ & & & & \\
\hline 5 & $\begin{array}{l}\text { Perceived Behavioral } \\
\text { Control (Difficult) }\end{array}$ & $\begin{array}{l}-.07 \\
-.14 \\
-.14 \\
-.09\end{array}$ & $\begin{array}{l}.13 \\
.04 \\
-.05 \\
.06\end{array}$ & $\begin{array}{l}.14 \\
.03 \\
-.03 \\
.20\end{array}$ & $\begin{array}{l}-.26 \\
-.16 \\
-.18 \\
-.48\end{array}$ & $\begin{array}{l}2.62(1.83) \\
3.04(1.88) \\
2.32(1.42) \\
2.02(1.88)\end{array}$ & & & \\
\hline 6 & Moral Obligation & $\begin{array}{l}.32 \\
.22 \\
.27 \\
.18\end{array}$ & $\begin{array}{l}.33 \\
.25 \\
.10 \\
.22\end{array}$ & $\begin{array}{l}.30 \\
.16 \\
.20 \\
.30\end{array}$ & $\begin{array}{l}.06 \\
.14 \\
.06 \\
-.04\end{array}$ & $\begin{array}{l}.12 \\
.05 \\
-.04 \\
.17\end{array}$ & $\begin{array}{l}3.39(1.86) \\
3.73(1.76) \\
3.72(1.80) \\
2.26(1.70)\end{array}$ & & \\
\hline 7 & Identity & $\begin{array}{l}.19 \\
.12 \\
.41 \\
.47\end{array}$ & $\begin{array}{l}.40 \\
.36 \\
.47 \\
.47\end{array}$ & $\begin{array}{l}.24 \\
.12 \\
.24 \\
.27\end{array}$ & $\begin{array}{l}.46 \\
.53 \\
.54 \\
.29\end{array}$ & $\begin{array}{l}.05 \\
.06 \\
-.08 \\
.02\end{array}$ & $\begin{array}{l}.18 \\
.18 \\
.13 \\
.21\end{array}$ & $\begin{array}{l}5.37(1.27) \\
5.52(1.31) \\
5.20(1.12) \\
5.23(1.29)\end{array}$ & \\
\hline 8 & $\begin{array}{l}\text { Intention to Work in } \\
\text { Alternative Career }\end{array}$ & $\begin{array}{l}-.35 \\
-.31 \\
-.17 \\
-.24\end{array}$ & $\begin{array}{l}-.23 \\
-.11 \\
-.18 \\
-.15\end{array}$ & $\begin{array}{l}-.15 \\
-.04 \\
-.24 \\
-.03\end{array}$ & $\begin{array}{l}-.07 \\
.00 \\
-.21 \\
-.09\end{array}$ & $\begin{array}{l}.08 \\
.11 \\
.10 \\
.08\end{array}$ & $\begin{array}{l}-.10 \\
-.04 \\
-.20 \\
.13\end{array}$ & $\begin{array}{c}-.07 \\
-.04 \\
-.18 \\
.05\end{array}$ & $\begin{array}{l}4.82(1.62) \\
4.70(1.58) \\
4.18(1.69) \\
5.58(1.40)\end{array}$ \\
\hline
\end{tabular}


NOTES:

1. In each cell, the four rows of data refer respectively to the whole sample ( $\mathrm{N}=978$ ), Unqualified ( $\mathrm{N}=507)$, In training ( $\mathrm{N}=244)$, and Qualified ( $\mathrm{N}=227)$.

2. $\quad$ Not all respondents specified an alternative career, so Ns for row 8 are 331, 205, 150 and 76.

3. For the sake of clarity, statistical significance is not shown. For rows $1-7$, for the whole sample, $\mathrm{p}<.05$ for correlations greater than \pm .07 , and $\mathrm{p}<.01$ for \pm .09 . Corresponding critical values of $\underline{r}$ for Unqualified group \pm .09 and \pm .12 , for In Training and Qualified groups \pm .13 and \pm .17 . For row 8, whole sample critical values of $\underline{r}$ are \pm .13 and \pm .18 ; for In Training group \pm .27 and \pm .35 , and for Qualified group \pm .23 and \pm .30 . All these critical values refer to 2-tailed significance. 
Table 3: Results of Multiple Regressions Predicting Occupational Intention

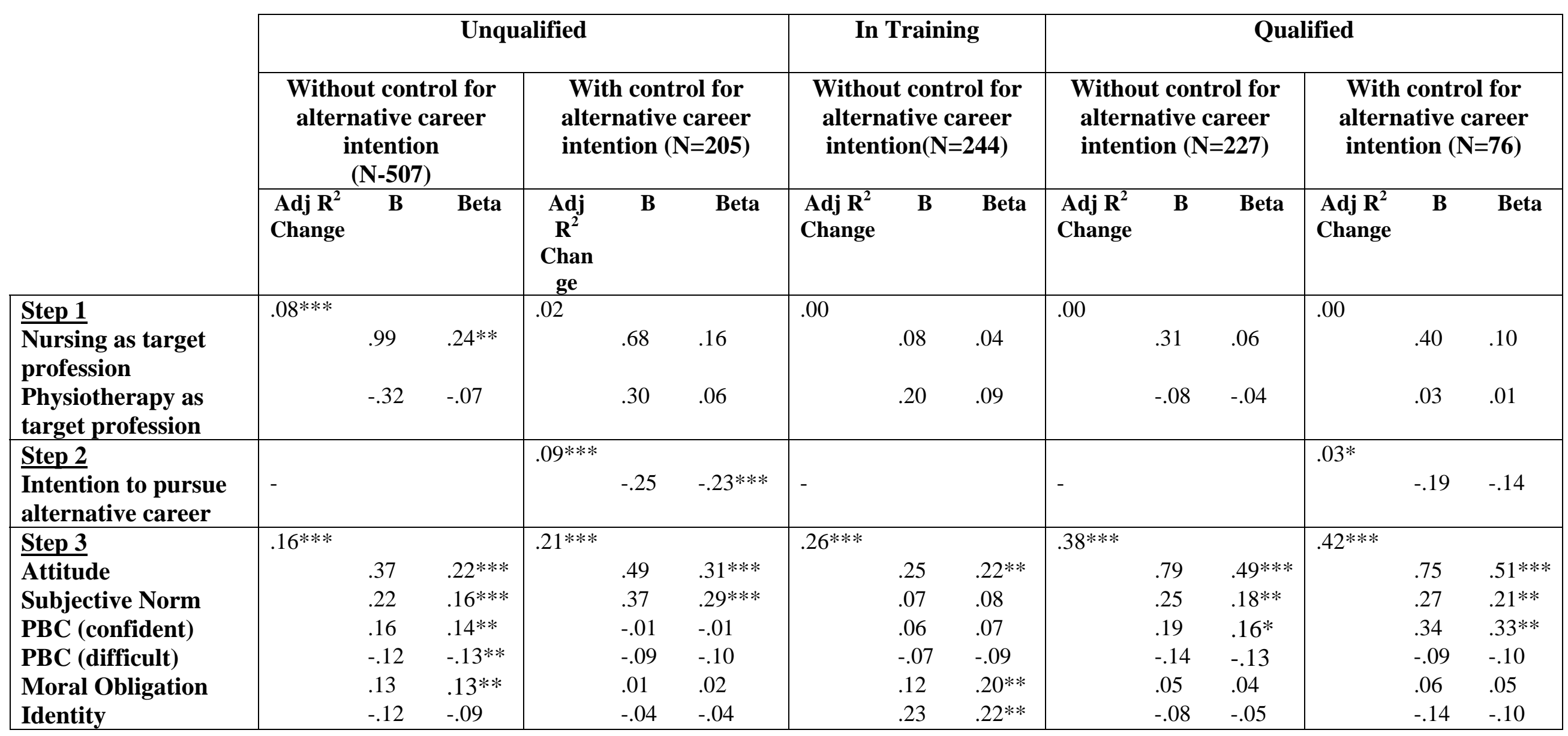

NOTES: Beta weights shown are in final equations.

Statistical significance: ${ }^{*} \mathrm{p}<.05 \quad * * \mathrm{p}<.01 \quad * * * \mathrm{p}<.001$ (all 2-tailed) 
Figure 1

\section{The Extended Theory of Planned Behavior (TPB)}

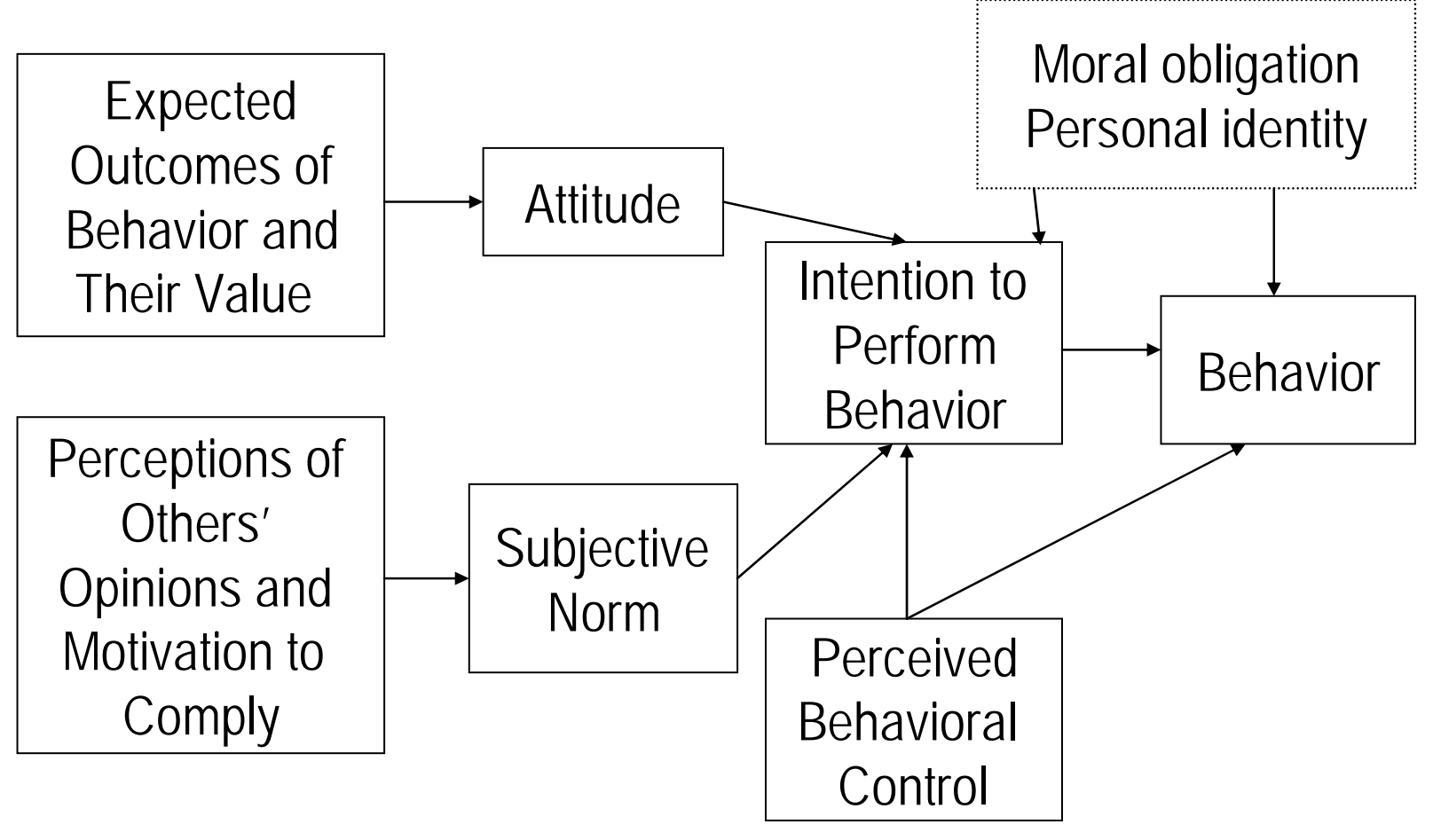

